\title{
Relationship between body mass index and simple visual reaction time in students of a medical college of Nepal
}

Neeti Bhat ${ }^{1}$, Narayan Bahadur Mahotra ${ }^{2}$, Lava Shrestha ${ }^{2}$, Vibina Aryal ${ }^{3}$, Nirmala Rayamajhi ${ }^{4}$, Sanyukta Gurung ${ }^{2}$

\section{Author(s) info:}

${ }^{1}$ Madan Bhandari Academy of Health Sciences, Hetauda, Nepal

${ }^{2}$ Department of Clinical Physiology, Maharajgunj Medical Campus, Institute of Medicine, Maharajgunj, Kathmandu, Nepal

${ }^{3}$ Department of Physiology, National Medical College, Birgunj, Nepal

${ }^{4}$ Nepal Police Hospital, Kathmandu

\section{Correspondence:}

Dr. Neeti Bhat, $M B B S, M D$

Madan Bhandari Academy of Health Sciences, Hetauda, Nepal

Email:

neetibhatbkt@gmail.com

DOI :

https://doi.org/10.3126/jpsn.v1i2.42286

\begin{abstract}
Introduction: Obesity is a chronic condition with an increase in adipose tissues. It is known to affect various systems of body including the central nervous system. Reaction time is a measure of the integrity of the central nervous system which is an integrated voluntary response to a stimulus that includes receiving and processing of stimulus, drawing inference, and generating a motor response. This study was conducted with the objective of finding a relationship between body mass index, a measure of obesity and simple visual reaction time.
\end{abstract}

Materials and methods: This cross-sectional analytical study was conducted on 60 participants aged 18-25 years. The body mass index of participants was calculated using Quetelet's index, calculated by weight in kilograms divided by square of height in meter. DearyLiewald reaction time task software version 3.10 was used to analyze their simple visual reaction time. Correlation of reaction time and body mass index was assessed using Pearson's correlation test.

Results: A weak positive correlation ( $\mathrm{r}=0.17)$ was observed between body mass index and simple visual reaction time but the correlation coefficient was not statistically significant $(\mathrm{p}=0.19)$.

Conclusions: Slower visual reaction time with an increase in body mass index was noted. But the findings of current study were inadequate to deduce if any linear relationship exists between simple visual reaction time and body mass index.

Keywords: BMI, obesity, simple visual reaction time

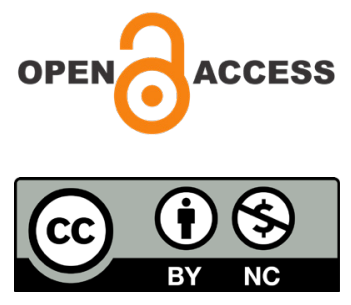

\section{○ JPSN}




\section{INTRODUCTION}

Obesity is a complex and multifactorial chronic disease characterized by excessive accumulation of adipose tissue. Body mass index (BMI) is popularly used method to determine, characterize and classify obesity.[1] Major surge in population with obesity has led to its pandemic level.[2] Today, children are more affected than adults and there is no success story in combating this humanitarian crisis in years. [3] The health consequences of obesity is multifaceted and overwhelming.[2] Evidences of altered and impaired cognition in obesity have been projected forward.[4,5]

Reaction time is a simple method to assess the processing capacity of the human brain. It measures how quickly a subject responds voluntarily to a stimulus given. It is expressed in milliseconds. Reaction time is used for evaluation of intactness of sensorimotor association along with cognition performance.[6-8] Francis Galton in the late $19^{\text {th }}$ century was among the first to study simple reaction time.[9]

Reaction time is dependent upon various factors such as age, gender, trauma, exercise, body-built, intelligence, cognition, and yoga. The two most commonly used methods to analyze reaction time are auditory and visual reaction times.[6] Studies have concluded that simple reaction time can be used to quantitatively analyze fluid intelligence across various populations.[10-12] Simple visual reaction time (SVRT) can be defined as the time between visual cues provided and split-second response to it.[6] Longer reaction time in obese subjects has been observed in various studies. $[13,14]$

Due to a limited number of studies available in the Nepalese population to find an association between obesity and reaction time, we undertook an effort to explore if such a relationship exists. We conducted this study to find an association between body mass index and simple visual reaction time.

\section{MATERIALS AND METHODS}

This was a quantitative cross-sectional analytical study conducted at the Department of Clinical Physiology, Maharajgunj Medical Campus, Kathmandu, Nepal. Students from different disciplines such as Bachelors of Medicine and Bachelors of Surgery, Bachelors of Dental Surgery and allied health sciences of Maharajgunj Medical Campus were the study population.

To maintain homogeneity of study participants, we included subjects of age group 18 to 25 years and right-handed subjects confirmed using Edinburgh handedness inventory. To remove the influence of confounding variables, we excluded subjects with any clinical conditions affecting cognition, mental illness impairing judgment, diminished or uncorrected visual acuity, color blindness, smoking and alcoholism, medication impairing cognition, pregnant and body builders.

The purpose of the study was explained to participants in Nepali and verbal consent from eligible participants was obtained. Subjects were asked to fill the self-administered questionnaire to yield more accurate data and minimize the interviewer's bias. The questions and responses were however clarified by researchers when not understood by study participants. Participants who met inclusion criteria were randomly recruited in the study using the randomization tool in MS Excel 2016 for Mac.

Participants were instructed to avoid caffeine, nicotine, and exercise prior to the test. The body mass index of subjects was calculated using Quetelet's index which is body mass in kilograms (Kgs) divided by square of body height in meter. The height of subjects was measured using a stadiometer. The weight of participants was recorded using an electronic weighing scale.

For evaluating the simple visual reaction time of subjects, the Deary-Liewald reaction time (DLRT) task software was used. This software was developed by IJ Deary and D Liewald at the University of Edinburgh Centre for Cognitive Ageing and Cognitive Epidemiology. For evaluation of simple visual reaction time, the participants had to press on the space bar as soon as the stimulus in the form of a cross appeared on the screen. The participants were allowed to practice the trial 5 times. They were allowed to rest for 5 minutes post-trial, after which the test was conducted. Altogether 20 visual cues were sent and 20 reaction times were noted in milliseconds (ms) with inter-stimulus interval of $1000 \mathrm{~ms}$. The DLRT software then generated a mean of simple visual reaction time from each participant.[11]

We used MS EXCEL 2016 for data entry. IBM SPSS Statistics for Macbook, version 16 (IBM Corp., 
Table 1: Distribution of subjects in different categories of BMI $(n=60)$

\begin{tabular}{|l|c|c|c|}
\hline \multicolumn{1}{|c|}{ Categories } & Values & Number (n) & Percentage (\%) \\
\hline Underweight & $<18.5 \mathrm{Kg} / \mathrm{m}^{2}$ & 7 & 11.66 \\
\hline Normal & $18.5-24.99 \mathrm{Kg} / \mathrm{m}^{2}$ & 51 & 85 \\
\hline Overweight & $>25 \mathrm{~kg} / \mathrm{m}^{2}$ & 2 & 3.33 \\
\hline Total & & 60 & \\
\hline
\end{tabular}

Table 2: SVRT in different categories of BMI

\begin{tabular}{|l|c|c|c|c|}
\hline \multirow{2}{*}{ Categories } & \multicolumn{4}{|c|}{ Simple Visual Reaction Time (ms) } \\
\cline { 2 - 5 } & Mean & Standard deviation & Minimum & Maximum \\
\hline Underweight & 244.71 & 13.96 & 221 & 266 \\
\hline Normal & 289.78 & 47.78 & 235 & 439 \\
\hline Overweight & 287 & 72.12 & 236 & 338 \\
\hline
\end{tabular}

Armonk, N.Y., USA) was used for data analysis. Categorical data were expressed in frequency and percentage whereas continuous data were expressed in mean \pm standard deviation. We used Pearson's correlation test to analyze if a linear relationship exists between simple visual reaction time and body mass index. The " $r$ " value thus obtained was used to interpret the finding. A probability value (p-value) less than 0.05 was considered to be statistically significant.

\section{RESULTS}

There were altogether 60 subjects recruited in the study, among them were 26 females and 34 males. The mean age of study participants was $20.20 \pm 1.60$ years and the mean BMI was $21.39 \pm 2.67 \mathrm{~kg} / \mathrm{m}^{2}$. Most of our study participants belonged to normal BMI (Table 1).

Our study participants had mean SVRT of $284.43 \pm 47.48 \mathrm{~ms}$ which ranged from 221 to $439 \mathrm{~ms}$ across different BMI groups (Table 2). The mean SVRT was found to be highest in normal BMI category and lowest in underweight BMI category.

Simple visual reaction time showed a weak positive correlation $(\mathrm{r}=+0.17)$ with body mass index (Figure $1)$. The correlation was however not statistically significant $(\mathrm{p}=0.19)$.

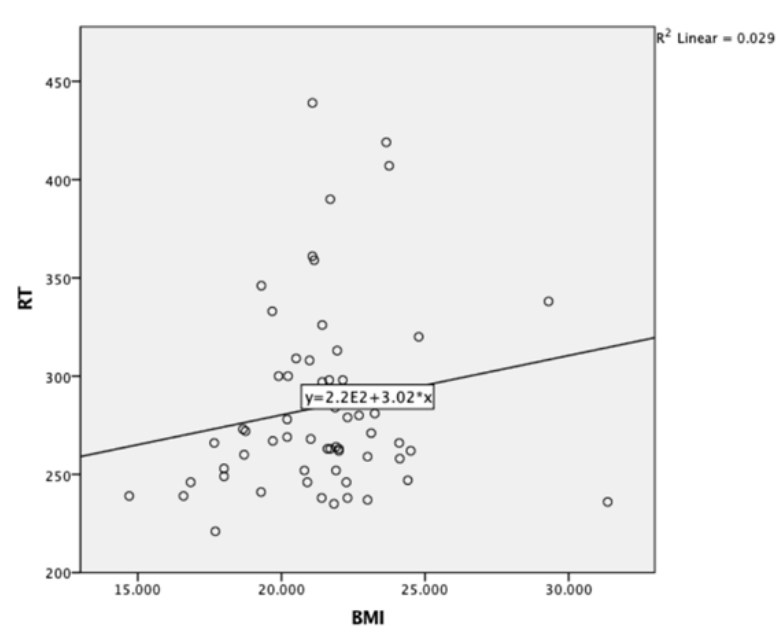

Figure 1: A scatter plot diagram showing correlation between body mass index and simple visual reaction time

\section{DISCUSSION}

Our study demonstrated a weak positive correlation between BMI and simple visual reaction time. An increase in BMI resulted in longer simple reaction time and the correlation was not statistically significant.

The mean age of our study participants was similar to existing literature.[15-17]. The mean BMI of our subjects is in line with previous studies. $[17,18]$ 
In accordance with existing studies, most subjects in our study belonged to a normal BMI category. $[14,16]$

The mean simple visual reaction time ties in well with the study by Ngo et al [16], where in a computer-based Human Benchmark program was used to evaluate the visual reaction time. Longer SVRT was observed in the current study when compared with a study by Nadeem et al. where audacity software was employed to record simple visual reaction time.[15] Likewise, Jha et al. also noticed shorter SVRT compared to ours.[17] The authors however used the ruler drop method to calculate SVRT. Latency to elicit a motor response to visual stimuli was shorter as seen in a study by Sudheer et al where a response analyzer (YSRT 0101 - Pune) was used.[18]

Contrary to the preceding findings, mean SVRT was highest in the normal BMI category.[14,19] The finding of a positive correlation between BMI and SVRT in the current study is consistent with earlier studies.[16,18,20] However, significant and moderately strong correlation between BMI and visual reaction time was noted by Nikam et al.[20] Weak positive correlation which is insignificant as observed in our study is substantiated by Sudheer et al.[18]

Nadeem et al explored the effects of obesity on central nervous system functioning and found out that reaction time was prolonged in subjects with higher BMI before and five minutes after unilateral nasal breathing.[15] Hence the author concluded on the deteriorating effect of obesity on central neuronal processing. In a study conducted by Moradi et al to seek out any existing relationship between obesity and reaction time among children, the author after controlling all possible confounders demonstrated that only body fat percentage correlated with reaction time.[9]

Obesity impairs bodily homeostasis such as lipid metabolism, insulin release, circadian rhythm, and other hormonal regulation. An increase in oxidative stress and underlying vascular disease in obese subjects impact cognitive functioning. [15,18] Earlier studies elucidated that nerve conduction latencies in obese were slower when contested with non-obese.[21,22]

In a systemic review and meta-regression analysis study conducted by Albanese et al, it was found out that higher BMI in midlife is associated with an increase in the risk of dementia.[23] The steep rise in the number of obese subjects and an aging population with the known accelerating effect of obesity on aging has given rise to a new concern known as "adipaging". [24] The cumulative effect of obesity and aging on the development of neurodegenerative disease might lead to its catastrophic prevalence and burden.

Some inherent limitations such as inability to draw a causal inference, difficulty in controlling confounders are the limitations of this study. It would be difficult to interpret if an association is identified. The finding thus needs to be interpreted with caution. Therefore, a longitudinal study addressing possible confounders with a larger sample size would be a novel research topic.

\section{CONCLUSION}

The conclusion of this study, although not statistically significant, is a slower simple visual reaction time with an increase in body mass index. But there is inadequate evidence to infer that any linear relationship exists between simple visual reaction time and body mass index.

\section{CONFLICT OF INTEREST}

None

\section{REFERENCES}

1. Hruby A, Ни FB. The epidemiology of obesity: a big picture. PharmacoEconomics. 2015 Jul;33(7):673-89.

2. Blïher M. Obesity: global epidemiology and pathogenesis. Nat Rev Endocrinol. 2019 May;15(5):288-98.

3. Ng M, Fleming T, Robinson M, Thomson B, Graetz N, Margono C, et al. Global, regional and national prevalence of overweight and obesity in children and adults 19802013: A systematic analysis. Lancet Lond Engl. 2014 Aug 30;384(9945):766-81.

4. Wang C, Chan JSY, Ren L, Yan JH. Obesity reduces cognitive and motor functions across the lifespan. Neural Plast. 2016 Jan 12;2016:e2473081.

5. Cook RL, O'Dwyer NJ, Donges CE, Parker HM, Cheng HL, Steinbeck KS, et al. Relationship between obesity and cognitive function in young women: The Food, Mood and Mind Study. J Obes. 2017;2017:5923862.

6. Jain A, Bansal R, Kumar A, Singh K. A comparative study of visual and auditory reaction times on the basis of gender and physical activity levels of medical first year students. Int J Appl Basic Med Res. 2015;5(2):124-7. 
7. Gandhi PH, Gokhale PA, Mehta HB, Shah CJ. A comparative study of simple auditory reaction time in blind (congenitally) and sighted subjects. Indian J Psychol Med. 2013;35(3):273-7.

8. Amatya $M$, Thapa $S$, Kasti $R$, Nepal O. Visual reaction time of drivers versus healthy adults: a comparative study. J Physiol Soc Nepal. 2020;1(1).

9. Johnson RC, McClearn GE, Yuen S, Nagoshi CT, Ahern FM, Cole RE. Galton's data a century later. Am Psychol. 1985 Aug 1;40(8):875-92.

10. Woods DL, Wyma JM, Yund EW, Herron TJ, Reed B. Factors influencing the latency of simple reaction time. Front Hum Neurosci. 2015;9.

11. Schulz-Zhecheva Y, Voelkle MC, Beauducel A, Biscaldi $M$, Klein C. Predicting fluid intelligence by components of reaction time distributions from simple choice reaction time tasks. J Intell. 2016 Sep;4(3):8.

12. Meiran N, Shahar N. Working memory involvement in reaction time and its contribution to fluid intelligence: An examination of individual differences in reaction-time distributions. Intelligence. 2018 Jul 1;69:176-85.

13. Moradi A, Esmaeilzadeh $S$. Simple reaction time and obesity in children: whether there is a relationship? Environ Health Prev Med. 2017;22(2).

14. Deore DN, Surwase SP, Masroor S, Khan ST, Kathore V. A cross sectional study on the relationship between the body mass index (BMI) and the audiovisual reaction time (ART). J Clin Diagn Res JCDR. 2012 Nov;6(9):1466-8.

15. Nadeem S, Herur A. Correlation of body mass index with reaction time in unilateral forced nostril breathing: A randomized controlled trial. Medica Innov. 2019 Jun;8(1):26-33.

16. Ngo CW, Loh HY, Choo GA, Vellasamy R, Anparasan M. Influence of body mass index on visual reaction time: $A$ cross-sectional analytical study. BJMMR. 2015;10(3):1-8.

17. Jha RK, Thapa S, Kasti R, Nepal O. Influence of body mass index, handedness and gender on ruler drop method reaction time among adults. J Nepal Health Res Counc. 2020 Mar;18(46):108-11.

18. Sudheer C, Jagadeesan S, Kammar FK. Impact of BMI on visual reaction time in individuals with BMI in normal range. Int J Physiol. 2017;5(2):10.

19. Skurvydas A, Gutnik B, Zuoza AK, Nash D, Zuoziene IJ, Mickeviciene D. Relationship between simple reaction time and body mass index. JComp Hum Biol. 77-85;60(1).

20. Nikam LH, Gadkari JV. Effect of age, gender and body mass index on visual and auditory reaction times in Indian population. Indian J Physiol Pharmacol. 2012 Mar;56(1):94-9.

21. Majumdar S, Chaudhuri A, Ghar M, Rahaman WB, Hai A. Effect of obesity on nerve conduction study in an urban population of a developing country. Saudi J Sports Med. $2017 \operatorname{Sep} 1 ; 17(3): 162$.

22. Thakker D, Shah NJ, Trivedi RS. To Study The effect of bmi on nerve conduction velocity. Int J Basic Appl Physiol. 2019;8(1):73-7.

23. Albanese E, Launer LJ, Egger $M$, Prince MJ, Giannakopoulos P, Wolters FJ, et al. Body mass index in midlife and dementia: Systematic review and metaregression analysis of 589,649 men and women followed in longitudinal studies. Alzheimers Dement Amst Neth. 2017;8:165-78.

24. Pérez LM, Pareja GH, Sanchis GF, Emanuele E, Lucia A, Gálvez BG. 'Adipaging': ageing and obesity share biological hallmarks related to a dysfunctional adipose tissue. J Physiol. 2016 Jun 15;594(12):3187-207. 